\title{
Multiple threading of a triple-calix[6]arene host
}

\author{
Veronica luliano, Roberta Ciao, Emanuele Vignola, Carmen Talotta ${ }^{*}$ Patrizia lannece, \\ Margherita De Rosa, Annunziata Soriente, Carmine Gaeta and Placido Neri
}

\author{
Letter \\ Address: \\ Laboratory of Supramolecular Chemistry, Dipartimento di Chimica e \\ Biologia " A. Zambelli", Università di Salerno, Via Giovanni Paolo II \\ 132, 84084 Fisciano (Salerno), Italy \\ Email: \\ Carmen Talotta* - ctalotta@unisa.it \\ * Corresponding author \\ Keywords: \\ calixarene; multiple-threading; pseudo[n]rotaxane; stereoisomers
}

Beilstein J. Org. Chem. 2019, 15, 2092-2104.

doi:10.3762/bjoc. 15.207

Received: 07 May 2019

Accepted: 16 August 2019

Published: 03 September 2019

This article is part of the thematic issue "Novel macrocycles - and old ones doing new tricks".

Guest Editor: W. Jiang

(C) 2019 luliano et al.; licensee Beilstein-Institut.

License and terms: see end of document.

\section{Abstract}

The synthesis of the triple-calix[6]arene derivative 6 in which three calix[6]arene macrocycles are linked to a central 1,3,5trimethylbenzene moiety is reported. Derivative $\mathbf{6}$ is able to give multiple-threading processes in the presence of dialkylammonium axles. The formation of pseudo[2]rotaxane, pseudo[3]rotaxane, and pseudo[4]rotaxane by threading one, two, and three, respectively, calix-wheels of 6 has been studied by 1D and 2D NMR, DOSY, and ESI-FT-ICR MS/MS experiments. The use of a directional alkylbenzylammonium axle led to the stereoselective formation of endo-alkyl pseudo $[n]$ rotaxane stereoisomers.

\section{Introduction}

The self-assembly [1] of smaller components to larger aggregates represents one of the most spectacular phenomena in supramolecular chemistry [2-4]. Among the self-assembly processes, those that lead to the formation of interlocked and/or interpenetrated supramolecular structures have inspired many scientists [5-8]. The synthesis of interlocked molecules such as rotaxanes, catenanes, and high-order architectures (e.g., polyrotaxanes, suitanes, daisy-chain pseudorotaxanes, olympiadane, Janus rotaxanes [5]) is generally obtained through a templateapproach [9] exploiting the threading process between linear (axle) and macrocyclic (wheel) components. In order to synthesize high-order interpenetrated architectures, much attention has been directed towards the study of multiple-threading processes of host systems bearing multiple-wheels (multivalent hosts). On this basis, interesting handcuff-like interpenetrated systems (Figure 1) have been reported to date in literature [1016], which represent non-trivial architectures.

Historically, the most common components were dialkylammonium ions, as axles, and crown ethers, cyclodextrins, or cucurbiturils, as wheels [1]. With respect to the possible types of wheels, more recently, we have introduced the through-theannulus threading of simple calix[6]arene hosts with dialkylammonium axles [17-26] by exploiting the inducing effect of the 

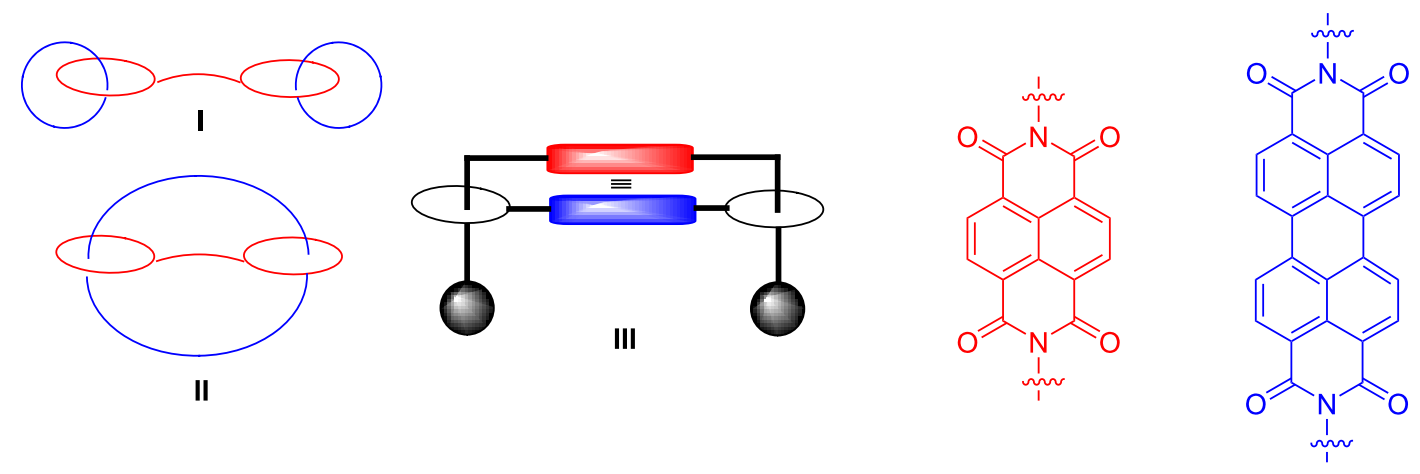

Figure 1: Sketch of the currently known prototypical examples of handcuff-derived architectures.

superweak tetrakis[3,5-bis(trifluoromethyl)phenyl]borate (TFPB) anion that gives free 'naked' dialkylammonium cations. In addition, we have reported interesting examples of endocavity complexation of alkylammonium cations, as $\mathrm{TFPB}^{-}$ salts, inside the aromatic cavity of calixarene [20] and dihomooxacalixarene hosts $[21,22]$. Thus, through this 'superweak anion' approach, we have synthesized interesting examples of calixarene/ammonium-based interlocked structures such as calix-rotaxanes $[23,24]$ and calix-catenanes [25]. On the basis of these results, we were also able to assemble high-order architectures by double-threading of bis-calix[6]arene hosts with ammonium axles [27]. In particular, handcuff (pseudo)rotaxane architectures (e.g., $\mathbf{3}^{\mathbf{2 +}}$ in Figure 2) [27] were obtained by double-threading of bis-calix[6]arene derivative 1 with bisammonium axles (e.g., $\mathbf{2}^{\mathbf{2}+}$ ). In addition, we have also shown that the bis-calix[6]arene $\mathbf{1}$ was able to form pseudo[3]rotaxane architectures (e.g., $\mathbf{5}^{\mathbf{2 +}}$ in Figure 2) by double-threading with dialkylammonium axles [28].

With the aim to increase the complexity of our system we have designed the triple-calix[6]arene host 6 (Figure 2) bearing three calix[6]arene wheels symmetrically-linked to a central benzene unit. Now the question arises as to whether the triplecalix[6]arene system 6 is also capable to form pseudo[n]rotaxanes by multiple-threading with dialkylammonium axles.

\section{Results and Discussion}

The synthesis of triple-calix[6]arene derivative $\mathbf{6}$ is outlined in Scheme 1.

The known pentamethoxycalix[6]arene-mono-ol derivative 9 $[29,30]$ was reacted with 1,3,5-tris(bromomethyl)benzene in the presence of $\mathrm{NaH}$ as base, in a mixture of dry THF/DMF (7/3 $\mathrm{v} / \mathrm{v}$ ) for $12 \mathrm{~h}$ at reflux. An HR-ESI-FT-ICR mass spectrum confirms the formation of $\mathbf{6}$ thanks to the presence of a molecular ion peak at $3283.1748 \mathrm{~m} / \mathrm{z}$ (calcd 3283.1319 for $\left.\mathrm{C}_{222} \mathrm{H}_{288} \mathrm{KO}_{18}{ }^{+}\right) .{ }^{1} \mathrm{H}$ and ${ }^{13} \mathrm{C}$ NMR spectra of 6 were consis- tent with the $C_{3}$-symmetry of the molecule. In details, three singlets were present in the ${ }^{1} \mathrm{H}$ NMR spectrum of $\mathbf{6}$ in $\mathrm{CDCl}_{3}$ at $298 \mathrm{~K}$ at $0.95(27 \mathrm{H}), 1.05(54 \mathrm{H})$, and $1.22 \mathrm{ppm}(81 \mathrm{H}=$ $54 \mathrm{H}+27 \mathrm{H}$; accidentally isochronous) attributable to tert-butyl groups, and three singlets at $2.56,2.80$, and $3.12 \mathrm{ppm}$ in a $2: 1: 2$ ratio, attributable to OMe groups were also found. The methylene benzylic resonance of 6 was revealed at 5.03 ppm. Finally, three AX systems were detected at $4.47 / 3.55(J=14.7 \mathrm{~Hz})$, $4.14 / 3.65(J=14.5 \mathrm{~Hz})$, and 4.01/3.80 $(J=14.2 \mathrm{~Hz}) \mathrm{ppm}$, attributable to the $\mathrm{ArCH}_{2} \mathrm{Ar}$ groups of the equivalent calix[6]arene wheels. The formation of pseudo[n]rotaxanes (Scheme 2 ) by threading of 6 with dibenzylammonium axle $7^{+}$ was studied by HR-ESI-FT-ICR mass spectrometry and $1 \mathrm{D} / 2 \mathrm{D}$ NMR (Figure 3). A 1:1 mixture of 6 and $7^{+} \cdot \mathrm{TFPB}^{-}$in $\mathrm{CHCl}_{3}$ was stirred at $298 \mathrm{~K}$ for $15 \mathrm{~min}$, until the solution was clarified, and then used for mass spectrometry analysis. An ESI-FT-ICR mass spectrum of this solution (Figure 3, bottom) revealed the presence of a molecular ion peak at $3442.2979 \mathrm{~m} / \mathrm{z}$ (calcd 3442.2965 for $\mathrm{C}_{236} \mathrm{H}_{308} \mathrm{NO}_{18}{ }^{+}$) attributable to the singlethreaded $7^{+} \subset 6$ pseudo[2]rotaxane.

The ${ }^{1} \mathrm{H}$ NMR spectrum (Figure 3, top) of the 1:1 mixture of 6 and $7^{+} \cdot \mathrm{TFPB}^{-}$in $\mathrm{CDCl}_{3}$ at $298 \mathrm{~K}$, clearly evidenced the formation of the $7^{+} \subset \mathbf{6}$ pseudo[2]rotaxane. In fact, a set of shielded benzyl resonances was observed in the 4.5-6.5 ppm region at $5.99(\mathrm{t}, 1 \mathrm{H}), 5.34(\mathrm{dd}, 2 \mathrm{H})$, and $4.77 \mathrm{ppm}(\mathrm{d}, 2 \mathrm{H})$, corresponding to its endo-cavity disposition and consequently indicative of the formation of the $7^{+} \subset \mathbf{6}$ pseudo[2]rotaxane. Two diagnostic broad singlets were present at $5.13 \mathrm{ppm}$ and $4.96 \mathrm{ppm}$ (1:2) attributable to the benzylic methylene groups of the central benzene core of $\mathbf{6}$ in $7^{+} \subset \mathbf{6}$ pseudo[2]rotaxane. A DOSY experiment (Figure 3, top) evidenced that the resonances in the ${ }^{1} \mathrm{H}$ NMR spectrum of the 1:1 mixture of 6 and $7^{+} \cdot$ TFPB $^{-}$in $\mathrm{CDCl}_{3}$ at $298 \mathrm{~K}$ all show the same diffusion coefficient of $7.06 \times 10^{-11} \mathrm{~m}^{2} / \mathrm{s}$ attributable to the $7^{+} \subset \mathbf{6}$ pseudo[2]rotaxane as $\mathrm{TFPB}^{-}$salt and significantly lower than that measured for the free triple-calix[6]arene host 6 of $3.02 \times 10^{-10} \mathrm{~m}^{2} / \mathrm{s}$. 

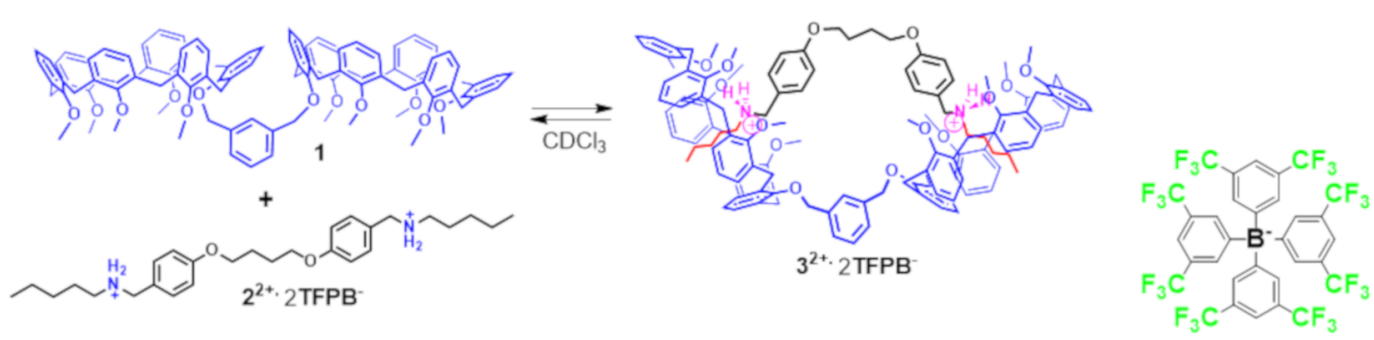

TFPB- Anion
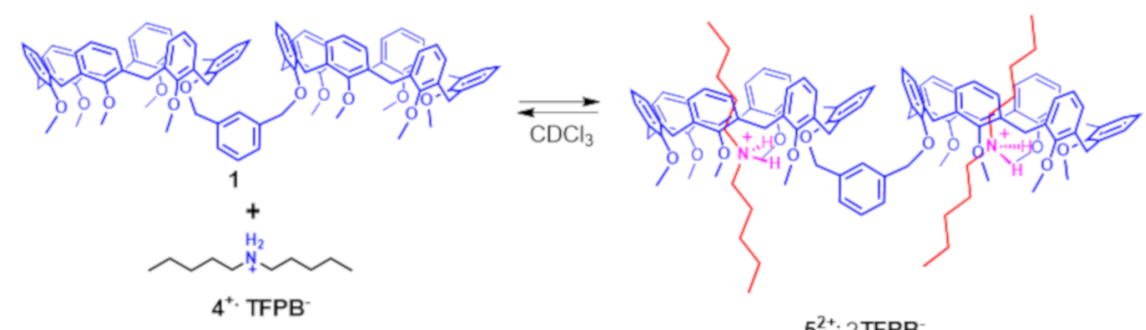

$5^{2+} \cdot 2$ TFPB $^{-}$

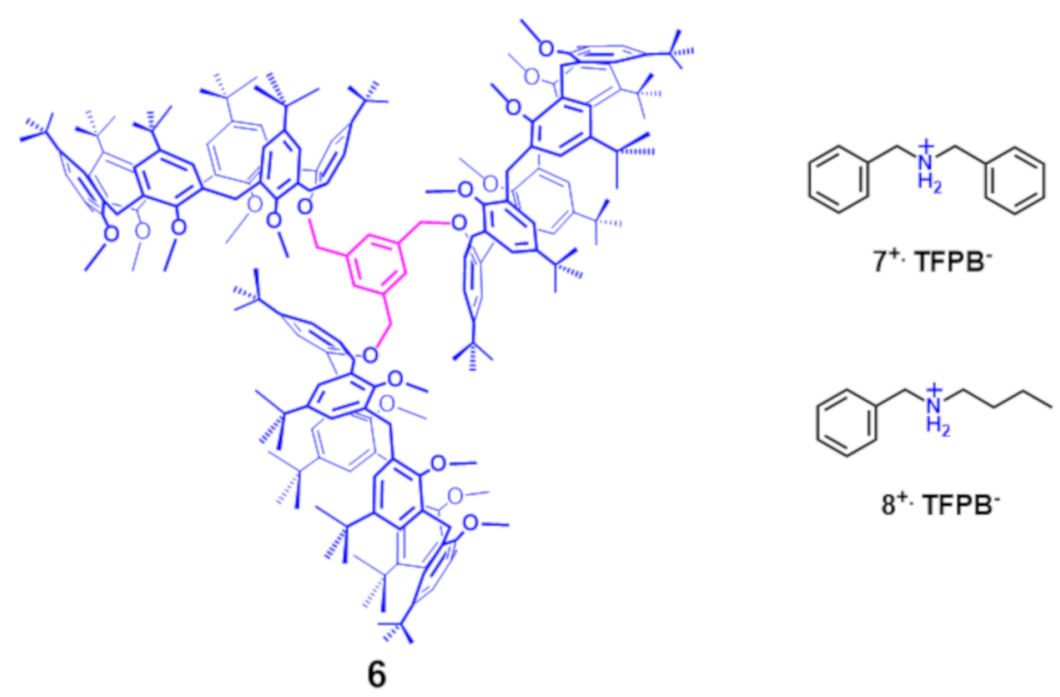

Figure 2: Chemical drawing of the known bis-calix[6]arene 1 and its handcuff pseudorotaxane architectures $3^{2+}$ and $5^{2+}$ previously reported. Structure of the triple-calix[6]arene host 6 studied in the present work.

Through an ${ }^{1} \mathrm{H}$ NMR quantitative analysis of a 1:1 mixture of $7^{+}$. $\mathrm{TFPB}^{-}$and 6 in $\mathrm{CDCl}_{3}$, using 1,1,2,2-tetrachloroethane as internal standard, an apparent association constant of $1.01 \pm 0.03 \times 10^{4} \mathrm{M}^{-1}$ was calculated for the $7^{+} \subset \mathbf{6}$ pseudo[2]rotaxane. When 1 equiv of $7^{+} \cdot \mathrm{TFPB}^{-}$salt was added to the $1: 1$ mixture of 6 and $7^{+} \cdot \mathrm{TFPB}^{-}$in $\mathrm{CDCl}_{3}$ (Figure $4 \mathrm{c}$ ), then, in addition to the benzylic resonances of the $7^{+} \subset \mathbf{6}$ pseudo[2]rotaxane at $5.13 \mathrm{ppm}$ and $4.96 \mathrm{ppm}$, two new broad singlets in a 1:2 ratio emerged at 5.08 and 5.06 ppm attributable to the benzylic methylene groups of the central benzene core of $\mathbf{6}$ in the double-threaded $\left(7^{+}\right)_{2} \subset \mathbf{6}$ pseudo[3]rotaxane (Scheme 2).
These data suggested that in a 1:2 mixture of 6 and $7^{+} \cdot \mathrm{TFPB}^{-}$in $\mathrm{CDCl}_{3}$ (Figure $3 \mathrm{c}$ ), were present both the $7^{+} \subset \mathbf{6}$ and $\left(7^{+}\right)_{2} \subset \mathbf{6}$ pseudorotaxanes, as confirmed by the ESI-FT-ICR mass spectrum in Figure 5, which revealed the presence of two ion peaks at 3442.2979 (calcd 3442.2965 for $\mathrm{C}_{236} \mathrm{H}_{308} \mathrm{NO}_{18}{ }^{+}$) indicative of the formation of the single-charged $7^{+} \subset \mathbf{6}$ and doublecharged $\left(7^{+}\right)_{2} \subset 6$ pseudo[3]rotaxanes, respectively. At this point, we performed the ESI-CID MS/MS experiment in Figure 5 , in order to confirm the formation of $\left(7^{+}\right)_{2} \subset 6$ pseudo[3]rotaxane. The CID mass spectrum of $\left(7^{+}\right)_{2} \subset \mathbf{6}$ (Figure 5) revealed the de-threading of one dibenzylammonium axle and the formation of the single-threaded $7^{+} \subset 6$ 


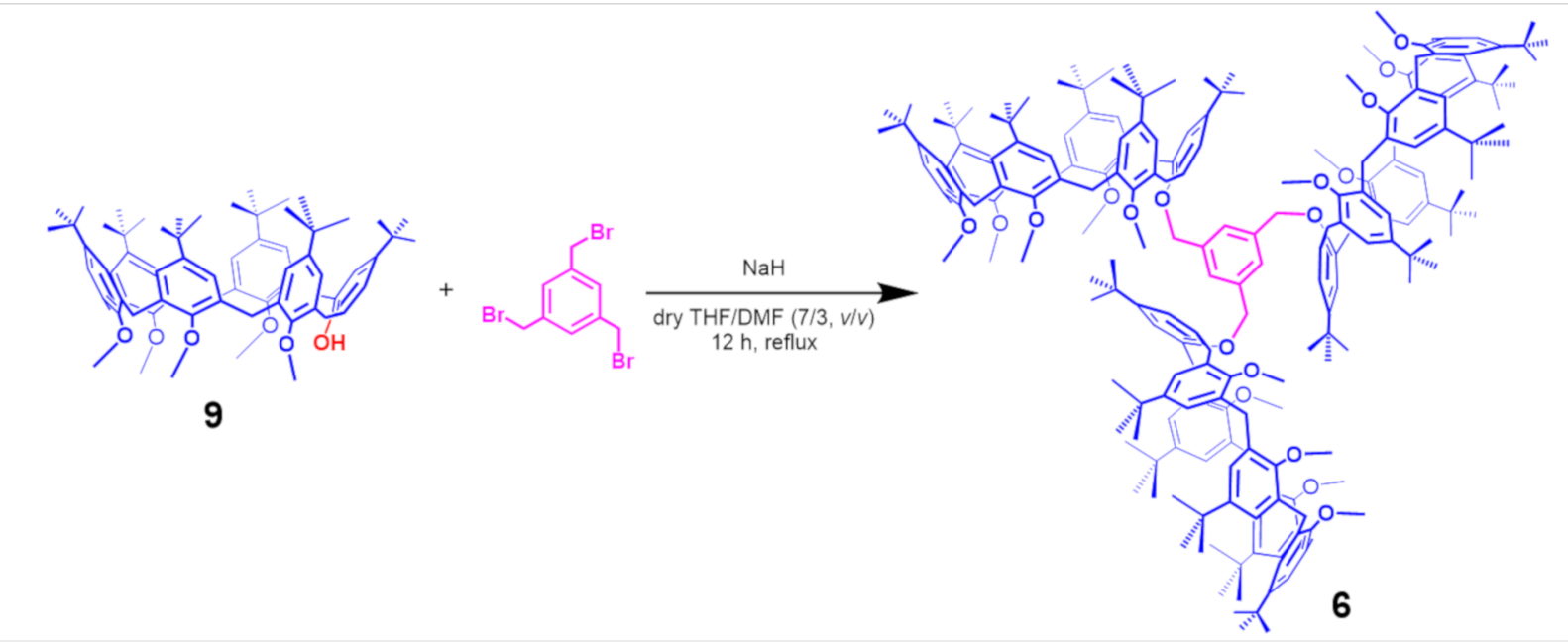

Scheme 1: Synthesis of triple-calix[6]arene host 6.

\section{$6+7^{+\cdot}$ TFPB $^{-}$}
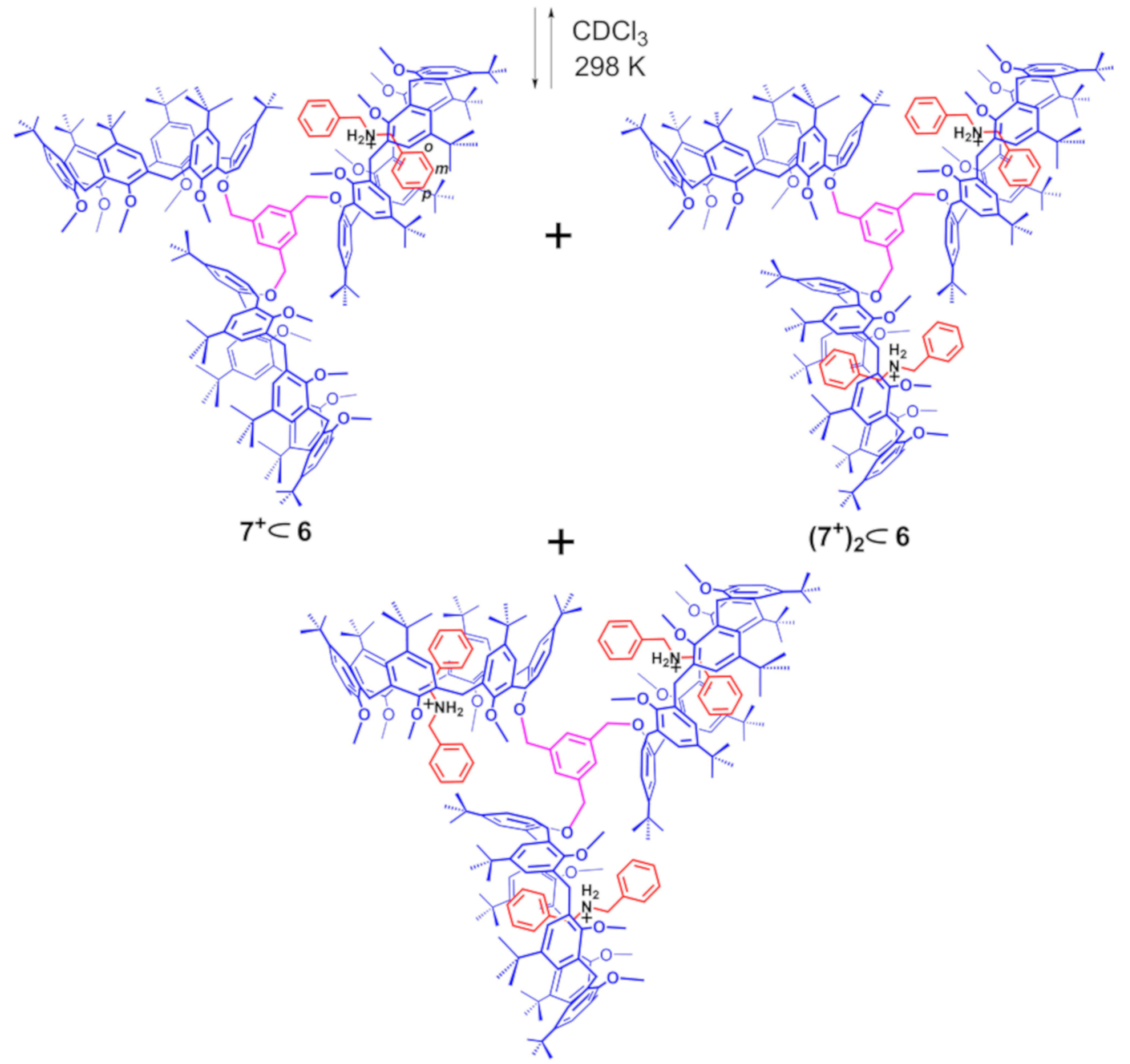

$\left(7^{+}\right)_{3}<6$

Scheme 2: Formation of the $7^{+} \subset 6,\left(7^{+}\right)_{2} \subset 6,\left(7^{+}\right)_{3} \subset 6$ pseudorotaxane architectures by multiple-threading of 6 with $7^{+}$as TFPB- salt. 

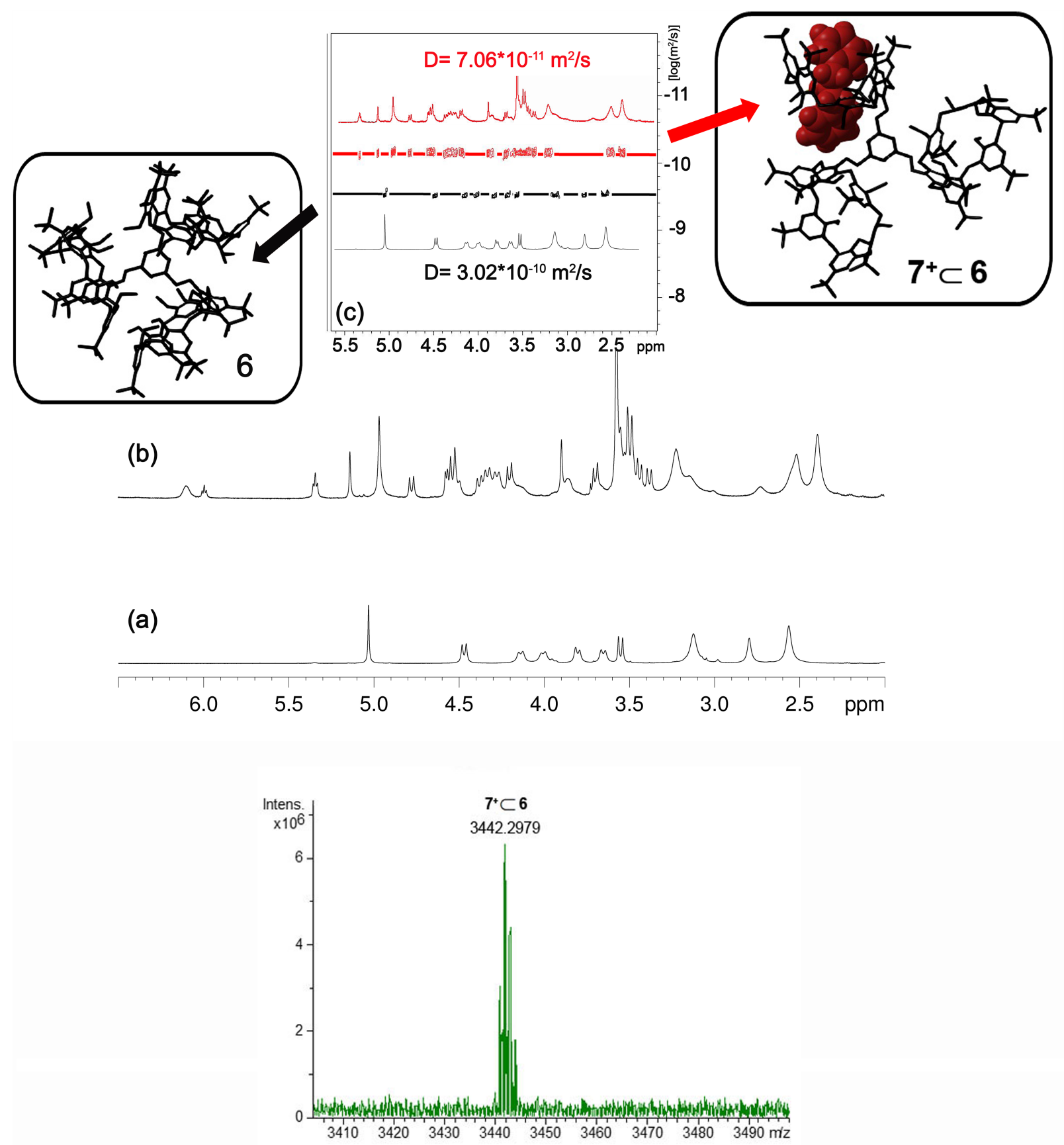

Figure 3: (Bottom) Portion of the ESI-FT-ICR mass spectrum of $7^{+} \subset \mathbf{6}$. (Top a-c) Significant portions of: (a) ${ }^{1} \mathrm{H}$ NMR spectrum of 6 (CDCl ${ }_{3}, 298 \mathrm{~K}$, $600 \mathrm{MHz}) ;\left(\right.$ b) ${ }^{1} \mathrm{H}$ NMR spectrum of a 1:1 mixture of 6 and $7^{+} \cdot \mathrm{TFPB}^{-}\left(\mathrm{CDCl}_{3}, 298 \mathrm{~K}, 600 \mathrm{MHz}\right)$; (c) DOSY spectra of 6 (black line) and a $1: 1$ mixture of 6 and $7^{+} \cdot$ TFPB $^{-}$(red line). Inset: structures of the triple-calix[6]arene 6 and $7^{+} \subset \mathbf{6}$ pseudo[2]rotaxane obtained by molecular mechanics calculations.

pseudo[2] rotaxane ion with $3442.2979 \mathrm{~m} / z$ (calcd. 3442.2965 for $\mathrm{C}_{236} \mathrm{H}_{308} \mathrm{NO}_{18}{ }^{+}$).

When a $6 / 7^{+} \cdot \mathrm{TFPB}^{-}$ratio of $1: 3$ was used (Figure $4 \mathrm{~d}$ ), then the double-threaded $\left(7^{+}\right)_{2} \subset 6$ pseudo[3]rotaxane was the species most abundant as evidenced by the presence of two singlet in $1: 2$ ratio at 5.08 and $5.06 \mathrm{ppm}$ attributable to the benzylic meth- ylene groups of the central benzene core of 6 in $\left(7^{+}\right)_{2} \subset 6$ pseudo[3]rotaxane (Scheme 2), which showed a ${ }^{1} J$ correlation in the HSQC spectrum with carbon resonances at 74.0 and $76.0 \mathrm{ppm}$. In addition, the ${ }^{1} \mathrm{H} \mathrm{NMR}$ spectrum in $\mathrm{CDCl}_{3}$, evidenced the presence of the shielded signals of the benzylic unit of the axles inside the calix-cavities at $6.02(\mathrm{t}, 1 \mathrm{H}), 5.36(\mathrm{br} \mathrm{t}$, $2 \mathrm{H})$, and $4.65 \mathrm{ppm}(\mathrm{d}, 2 \mathrm{H})$. A close inspection of the region be- 


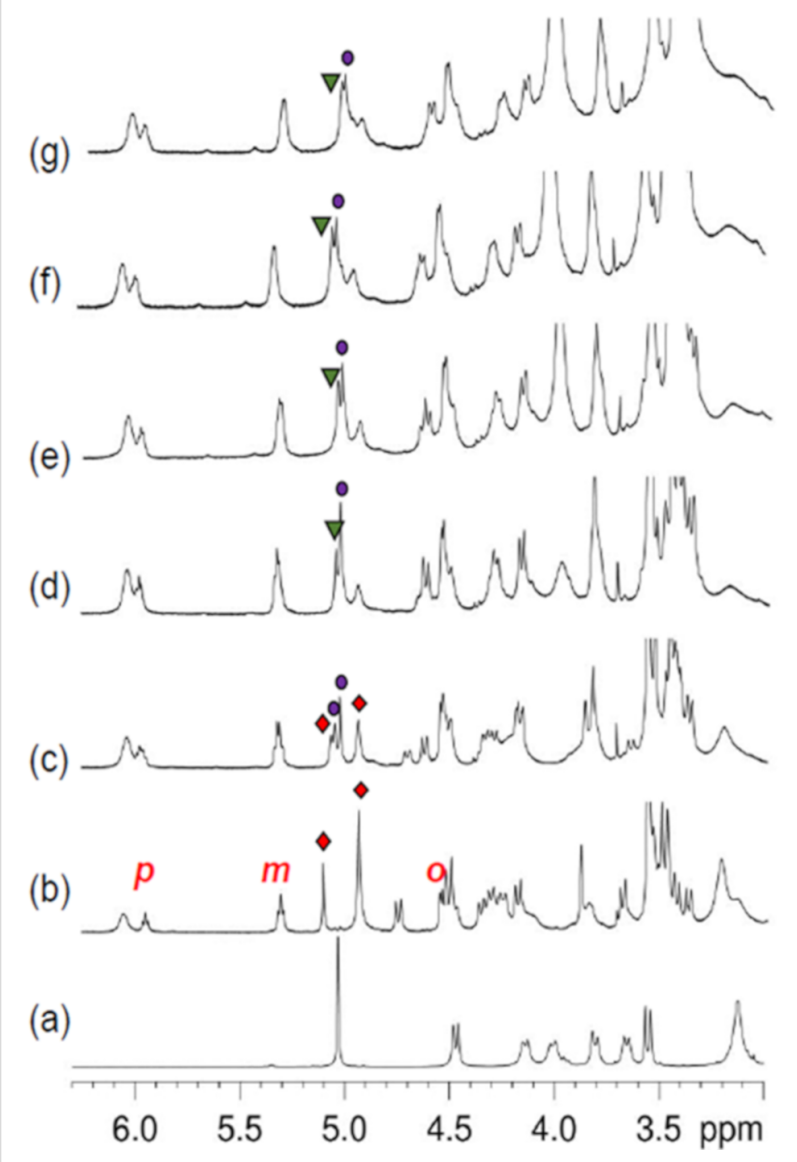

Figure 4: ${ }^{1} \mathrm{H}$ NMR titration of 6 with $7^{+} \cdot \mathrm{TFPB}^{-}\left(\mathrm{CDCl}_{3}, 298 \mathrm{~K}\right.$, $600 \mathrm{MHz}$ ). Significant portions of the ${ }^{1} \mathrm{H}$ NMR spectra of: (a) 6; (b) 1:1, (c) $1: 2$, (d) $1: 3$, (e) $1: 4$, (f) $1: 5$ and (g) $1: 6$ mixture of 6 and $7^{+} \cdot$ TFPB $^{-}$ Marked: red diamond $=7^{+} \subset 6$; purple circle $=\left(7^{+}\right)_{2} \subset 6$; green triangle $=\left(7^{+}\right)_{3} \subset 6$.

tween 3.0 and $5.0 \mathrm{ppm}$ of the COSY spectrum (Supporting Information File 1) of the $1: 3$ mixture of a 6 and $7^{+} \cdot \mathrm{TFPB}^{-}$evidenced the presence of 6 main $\mathrm{AX}$ systems attributable to the $\mathrm{ArCH}_{2} \mathrm{Ar}$ groups of $\mathbf{6}$ in $\left(7^{+}\right)_{2} \subset \mathbf{6}$ pseudo[3]rotaxane. An HSQC experiment revealed that these AX systems were ${ }^{1} J$ correlated with carbon resonances in the region $28-30 \mathrm{ppm}$, in details: $3.43 / 4.31 \rightarrow 27.9 \mathrm{ppm} ; 3.38 / 4.19 \rightarrow 28.0 \mathrm{ppm} ; 3.55 /$ $4.65 \rightarrow 29.2 \mathrm{ppm} ; 3.48 / 4.53 \rightarrow 30.4 \mathrm{ppm} ; 3.41 / 4.18 \rightarrow 30.0 \mathrm{ppm}$; $3.62 / 4.68 \rightarrow 29.2 \mathrm{ppm}$. Thus, these data clearly indicated that the calix[6]arene threaded by dibenzylammonium axles adopted a cone-conformation. A close inspection of the region between 4.8 and $5.2 \mathrm{ppm}$ in the $1 \mathrm{D}$ and 2D NMR spectra, revealed the presence of the triple-threaded $\left(7^{+}\right)_{3} \subset \mathbf{6}$ pseudo[4]rotaxane as a less abundant species. Therefore, these data indicate that in a $1: 3$ mixture of 6 and $7^{+} \cdot \mathrm{TFPB}^{-}$in $\mathrm{CDCl}_{3}$ (Figure $4 \mathrm{c}$ ), both $\left(7^{+}\right)_{2} \subset 6$ and $\left(7^{+}\right)_{3} \subset 6$ pseudorotaxanes are present. When the $7^{+} / 6$ ratio was increased from 3:1 to $6: 1$ (Figure $4 \mathrm{e}-\mathrm{g}$ ) then the benzylic resonance at $5.10 \mathrm{ppm}$ attributable to the triplethreaded pseudo[4]rotaxane $\left(7^{+}\right)_{3} \subset \mathbf{6}$ increased in intensity. In details, the shielded benzylic resonances attributable to the portion of the dibenzylammonium inside the calix-cavity were presents at $6.03,5.36$, and $4.53 \mathrm{ppm}$ and were ${ }^{1} J$-correlated in the HSQC spectrum with carbon resonances at 128.2, 127.3, and $128.6 \mathrm{ppm}$, respectively. The HSQC experiment also correlated the benzylic resonance at $5.10 \mathrm{ppm}$, attributable to the 1,3,5-trisubstitued benzene-core of 6 in $\left(7^{+}\right)_{3} \subset 6$ pseudorotaxane, with a carbon resonance at $76.0 \mathrm{ppm}$. In accord, COSY and HSQC experiments revealed the presence of three principal AX systems at 3.44/4.32, 3.39/4.22, and 3.58/4.66 ppm which were ${ }^{1} J$ correlated with carbon resonances at 27.7, 27.9, and $29.1 \mathrm{ppm}$, respectively, attributable to $\mathrm{ArCH}_{2} \mathrm{Ar}$ groups of calix[6]-wheels between syn oriented aromatic rings. Consequently, the three calix[6]-wheels in $\left(7^{+}\right)_{3} \subset \mathbf{6}$ adopt a cone conformation. This result was also confirmed by the minimumenergy structure of $\left(7^{+}\right)_{3} \subset \mathbf{6}$ obtained by molecular mechanics calculations (Figure 6), which evidenced the typical stabilizing $\mathrm{H}$-bonding interactions between the ammonium groups and the oxygen atoms of the calix[6]-wheels.

Analogous results were obtained when 6 was titrated with dipentylammonium axle $\mathbf{4}^{+}$, as $\mathrm{TFPB}^{-}$salt (Scheme 3 ). An
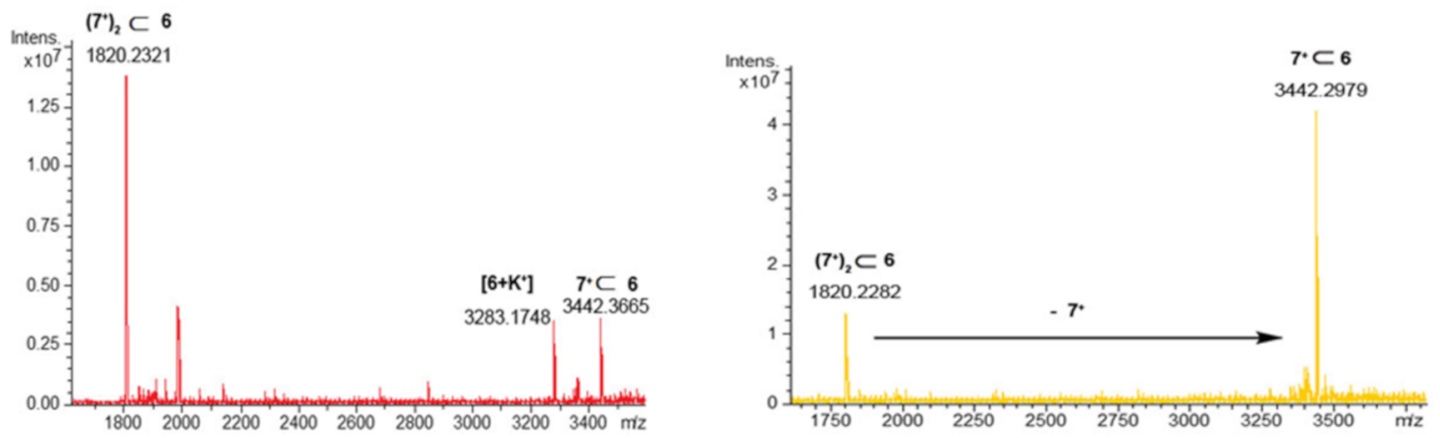

Figure 5: ESI-FT-ICR-MS and HR-ESI-FT-ICR-CID mass spectrum of $\left(7^{+}\right)_{2} \subset \mathbf{6}$. 


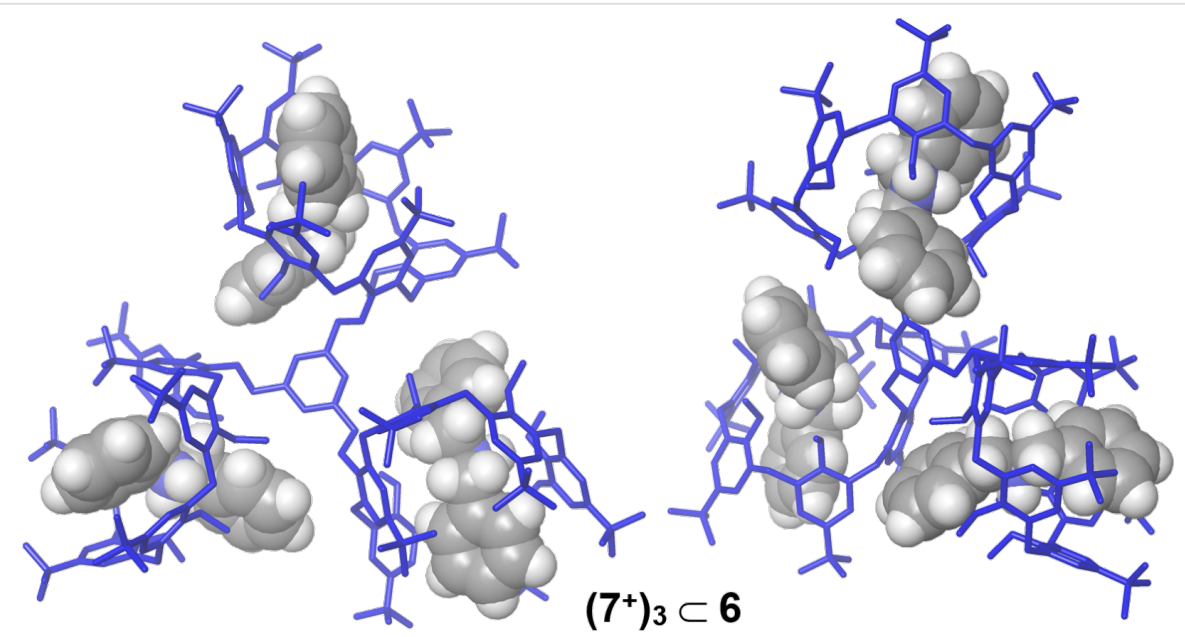

Figure 6: Different views of the minimized structures of $\left(7^{+}\right)_{3} \subset 6$ obtained by molecular mechanics calculations.

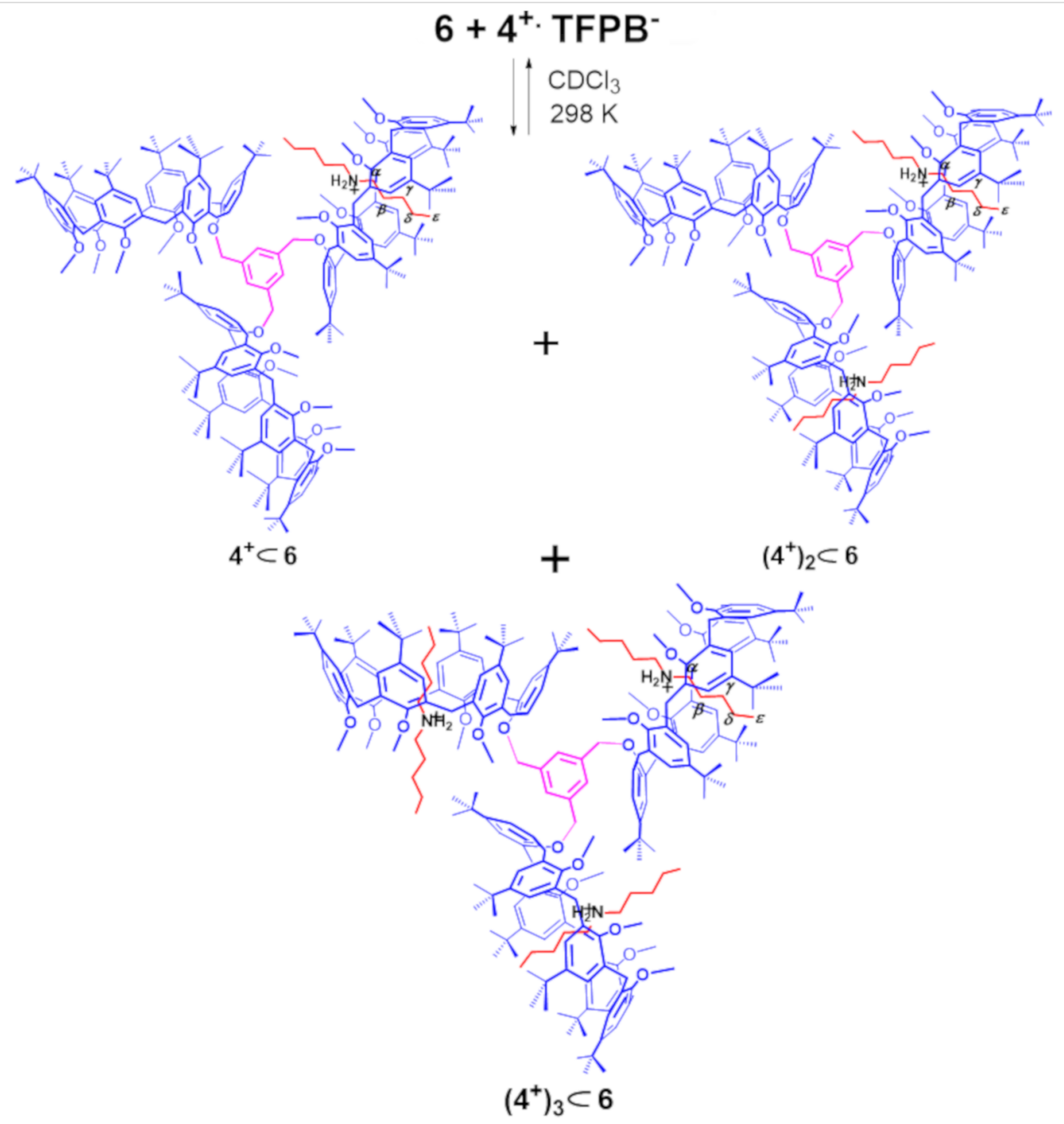

Scheme 3: Formation of the $4^{+} \subset 6,\left(4^{+}\right)_{2} \subset 6,\left(4^{+}\right)_{3} \subset 6$ pseudorotaxane architectures by multiple-threading of 6 with $4^{+}$as TFPB- salt. 
HR-ESI-FT-ICR mass spectrum (Figure 7e) of the 1:1 mixture of 6 and $4^{+}$. TFPB $^{-}$clearly evidenced the presence of a molecular ion peak at $3402.3809 \mathrm{~m} / \mathrm{z}$ (calcd 3402.3591 for $\mathrm{C}_{232} \mathrm{H}_{312} \mathrm{NO}_{18}{ }^{+}$) indicative of the formation of the singlecharged $4^{+} \subset \mathbf{6}$ pseudo[2]rotaxane. The ${ }^{1} \mathrm{H}$ NMR spectrum in $\mathrm{CDCl}_{3}$ of the $1: 1$ mixture of 6 and $4^{+} \cdot \mathrm{TFPB}^{-}$was also indicative of the formation of the single-threaded $4^{+} \subset \mathbf{6}$ pseudo[2] rotaxane (Figure 7b).

In fact, shielded signals at negative values of chemical shift were detected at $-0.99\left(\Delta \delta=\delta_{\text {free }}-\delta_{\text {complexed }}=2.69\right),-0.88$ $(\Delta \delta=2.58),-0.57(\Delta \delta=1.94),-0.40(\Delta \delta=1.32)$, and $0.64 \mathrm{ppm}(\Delta \delta=2.37) \mathrm{ppm}$ attributable, respectively, to the $\beta, \gamma$, $\delta$, $\varepsilon$, and $\alpha \mathrm{H}$-atoms of the pentyl chain of axle $4^{+}$inside the calix-cavity of 6 (Figure 7). An apparent association constant of $1.20 \pm 0.02 \times 10^{4} \mathrm{M}^{-1}$ was calculated for the $\mathbf{4}^{+} \subset \mathbf{6}$ pseudo[2]rotaxane, by ${ }^{1} \mathrm{H}$ qNMR analysis, a value comparable to that calculated for the dibenzylammonium-based $7^{+} \subset 6$ pseudo[2]rotaxane.

When the $1: 2$ mixture of $\mathbf{6} / \mathbf{4}^{+} \cdot \mathrm{TFPB}^{-}$was studied, the ESI-FTICR mass spectrum (Figure $8 \mathrm{f}$ ) clearly evidenced the presence of both single- $4^{+} \subset 6$ and double-charged $\left(4^{+}\right)_{2} \subset 6$ pseudorotaxanes. At this point, we performed an ESI-CID MS/MS experiment (Figure 7f) in which the $\left(\mathbf{4}^{+}\right)_{2} \subset \mathbf{6}$ pseudo[3]rotaxane was collisionally dissociated to give $4^{+} \subset 6$, by de-threading of one dipentylammonium axle. When an excess of $4^{+} \cdot \mathrm{TFPB}^{-}$salt was added to the $\mathrm{CDCl}_{3}$ solution of 6 then evidences for the formation of the $\left(4^{+}\right)_{3} \subset 6$ pseudo[4]rotaxanes was obtained by a ${ }^{1} \mathrm{H}$ NMR study (Figure 8d). A careful analysis of the $\mathrm{ArCH}_{2} \mathrm{Ar}$ region of these spectra evidenced again a syn orientation of the aromatic rings of calix[6]-wheels corresponding to a cone conformation, which was also confirmed by the minimum-energy structure of $\left(4^{+}\right)_{3} \subset \mathbf{6}$ obtained by molecular mechanics calculations (Figure 8).

As it is known $[17,18]$, the threading of directional (or constitutionally asymmetric) alkylbenzylammonium axles with directional calixarene-wheels, could generate two diastereoisomeric pseudo[2]rotaxanes (Figure 9) [31-37]. Our group previously reported $[17,18]$ some examples of directional threading of calix[6]-wheels [38] in which the endo-alkyl stereoisomer in Figure 9 is preferentially formed over the endo-benzyl one $[17,18]$. On the basis of these empirical observations, we have introduced the so-called "endo-alkyl rule" [39]: "threading of a directional alkylbenzylammonium axle through a hexaalkoxycalix[6]arene occurs with an endo-alkyl preference". Interestingly, the threading of the butylbenzylammonium axle $\mathbf{8}^{+}$with derivative 6 could generate two distinct stereoisomeric pseudorotaxanes (endo-alkyl or endo-benzyl) for each

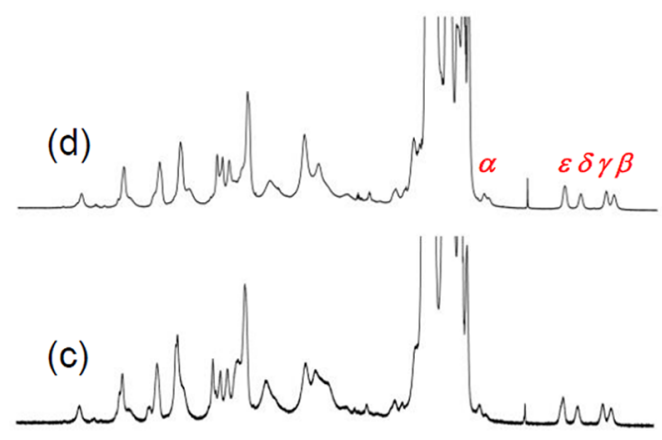

(e)
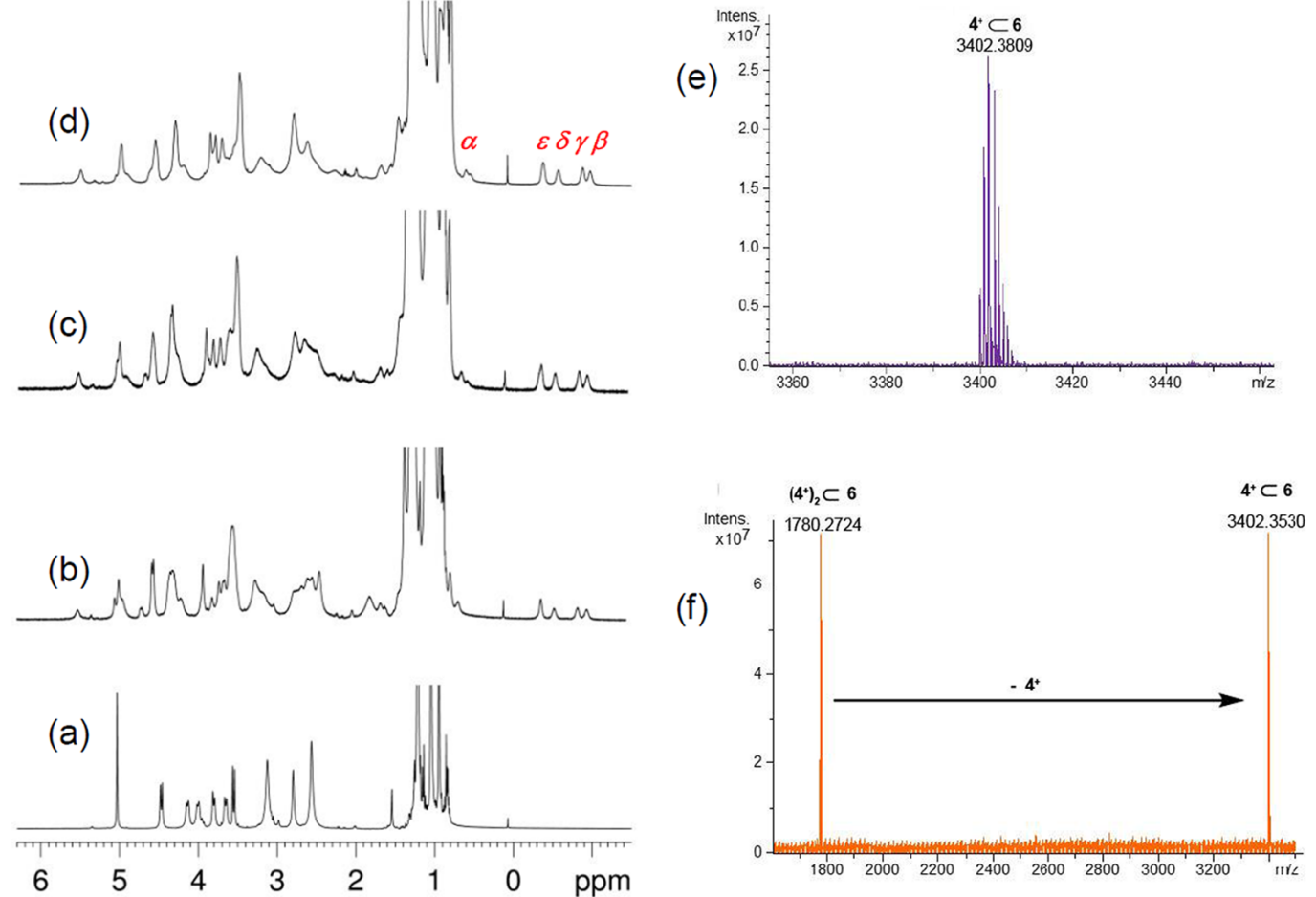

Figure 7: (a-d) ${ }^{1} \mathrm{H}$ NMR titration of 6 with $\mathbf{4}^{+} \cdot \mathrm{TFPB}^{-}\left(\mathrm{CDCl}_{3}, 298 \mathrm{~K}, 600 \mathrm{MHz}\right)$. Significant portions of the ${ }^{1} \mathrm{H}$ NMR spectra of: (a) 6; (b) 1:1, (c) 1:2, (d) $1: 3$, mixture of $\mathbf{6}$ and $\mathbf{4}^{+}$TFPB $^{-}$. (e) HR-ESI-FT-ICR mass spectrum of $\mathbf{4}^{+} \subset \mathbf{6}$. (f) HR-ESI-FT-ICR-CID mass spectrum of $\left(\mathbf{4}^{+}\right)_{2} \subset \mathbf{6}$. 

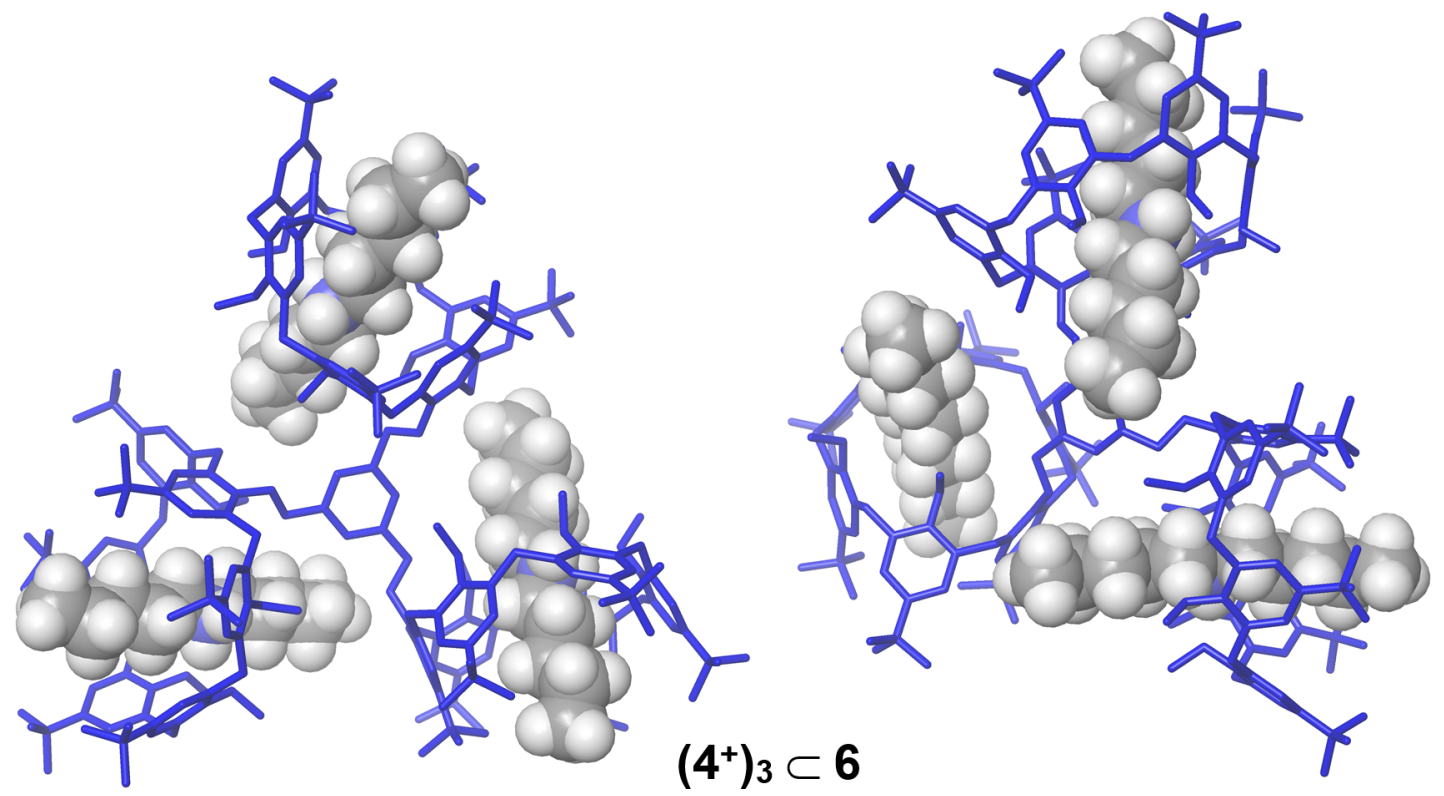

Figure 8: Different views of the minimized structures of $\left(4^{+}\right)_{3} \subset 6$ obtained by molecular mechanics calculations.

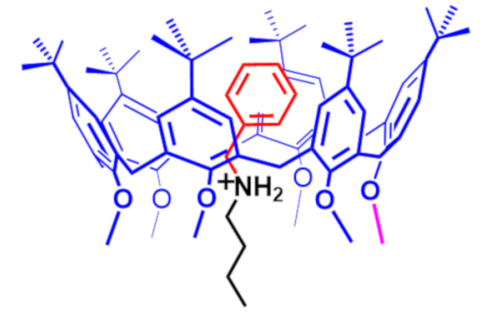

endo-benzyl

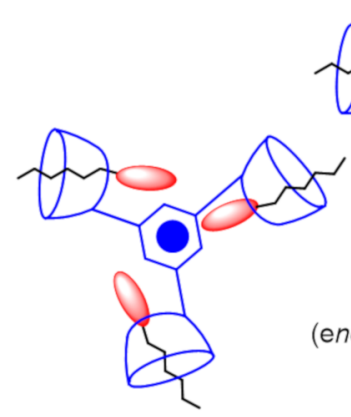

$($ endo-alkyl) 3

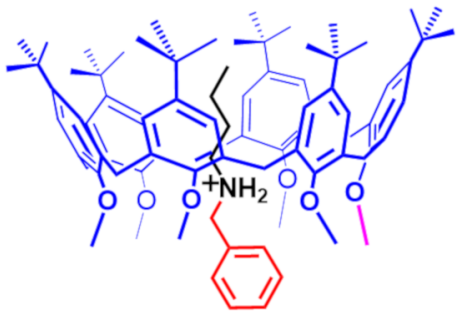

endo-alkyl
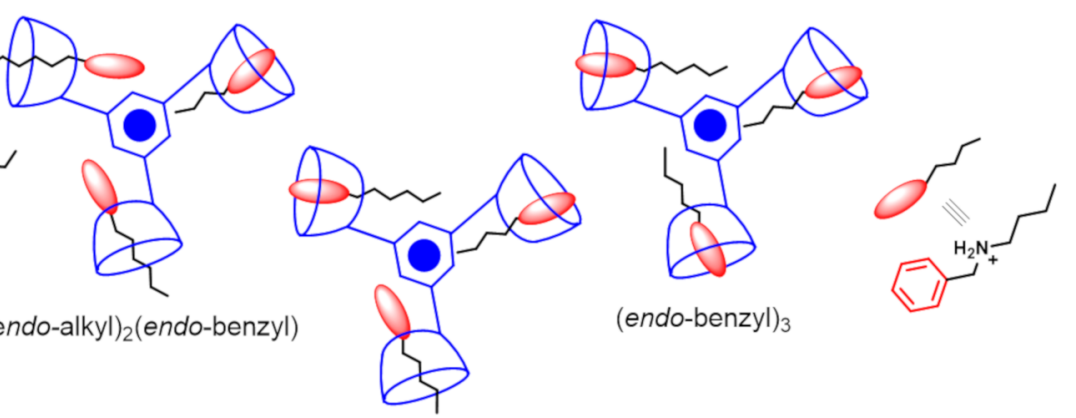

(endo-alkyl)(endo-benzyl) 2

Figure 9: (Top) Possible endo-benzyl and endo-alkyl stereoisomers obtainable by directional threading of calix[6]arene-wheel with alkylbenzylammonium axles. (Bottom) Sketch of the possible pseudo[4]rotaxane stereoisomers obtainable by triple-threading of 6 with $\mathbf{8}^{+}$.

calix[6]arene-wheel of $\mathbf{6}$, leading to a total of 4 possible stereoisomers, which are sketched in Figure 9.

When 1 equiv of butylbenzylammonium cation $\mathbf{8}^{+}$, as $\mathrm{TFPB}^{-}$ salt, was added to $\mathrm{a} \mathrm{CDCl}_{3}$ solution of $\mathbf{6}$, then the (endo-alkyl)$\mathbf{8}^{+} \subset \mathbf{6}$ pseudo[2]rotaxane was formed as indicated by the pres- ence in the ${ }^{1} \mathrm{H}$ NMR spectrum of shielded alkyl resonances at negative value of chemical shift between -0.73 to $-0.82 \mathrm{ppm}$. No evidence of the (endo-benzyl)-8 $\mathbf{8}^{+} \subset \mathbf{6}$ pseudo[2]rotaxane stereoisomer was detected in the ${ }^{1} \mathrm{H}$ NMR spectrum of the 1:1 mixture of $\mathbf{8}^{+}$and $\mathbf{6}$. An ESI-FT-ICR mass spectrum (Figure 10) of this mixture confirmed the formation of the 

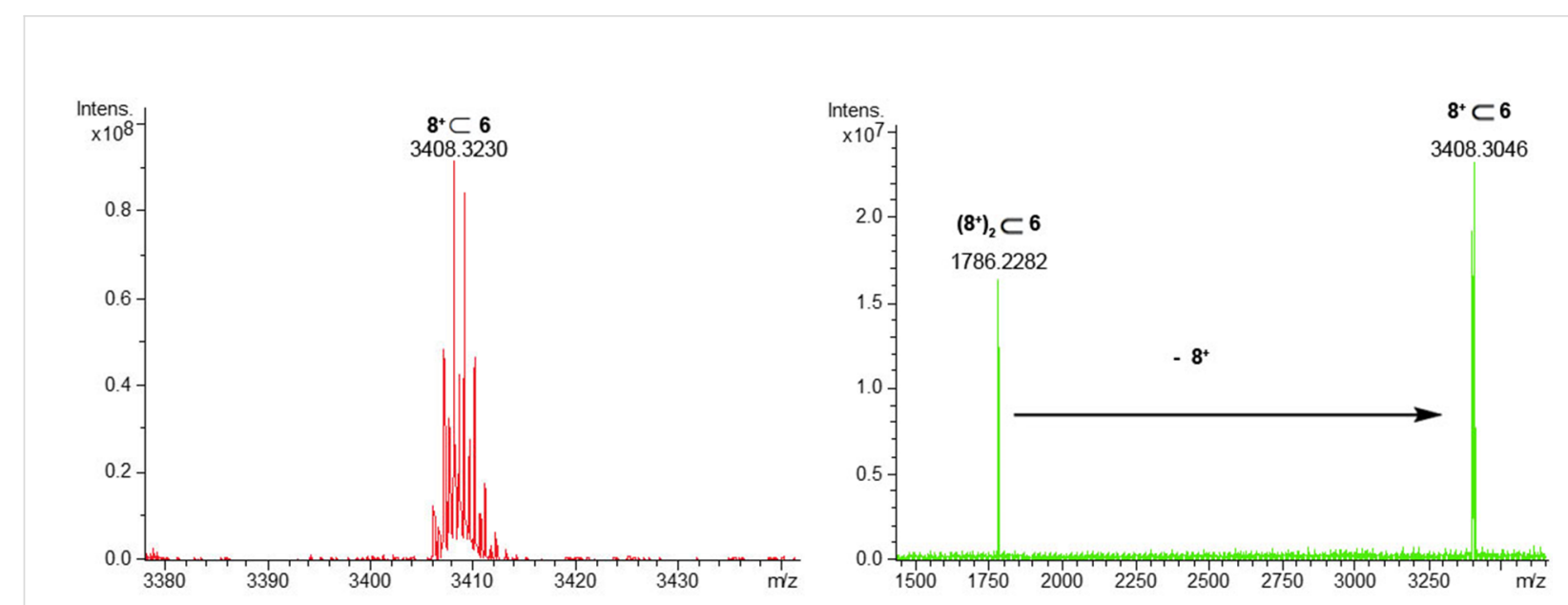

Figure 10: (Left) HR-ESI-FT-ICR mass spectrum of $\mathbf{8}^{+} \subset \mathbf{6}$. (Right) HR-ESI-FT-ICR-CID mass spectrum of $\left(8^{+}\right)_{2} \subset \mathbf{6}$.

$\mathbf{8}^{+} \subset \mathbf{6}$ pseudo[2]rotaxane by the presence of a molecular ion peak at $3408.3230 \mathrm{~m} / z$ (calcd 3408.3122 for $\mathrm{C}_{233} \mathrm{H}_{306} \mathrm{NO}_{18}{ }^{+}$). Finally, an apparent association constant of $5.70 \pm 0.03 \times 10^{2} \mathrm{M}^{-1}$ was calculated by ${ }^{1} \mathrm{H}$ qNMR analysis for the single-threaded $\mathbf{8}^{+} \subset \mathbf{6}$ pseudo[2]rotaxane, a value lower than that found for the dibenzylammonium- and dipentylammonium-based $\mathbf{7}^{+} \subset \mathbf{6}$ and $\mathbf{4}^{+} \subset \mathbf{6}$ pseudo[2]rotaxane.

Also in this case, an ESI-FT-ICR mass spectrum of the 1:2 mixture of $6 / \mathbf{8}^{+}$. TFPB $^{-}$evidenced the presence of both single$8^{+} \subset \mathbf{6}$ and double-charged $\left(8^{+}\right)_{2} \subset \mathbf{6}$ pseudorotaxanes. An ESICID MS/MS experiment revealed that the $\left(8^{+}\right)_{2} \subset \mathbf{6}$ pseudo[3]rotaxanes was collisionally dissociated to $8^{+} \subset \mathbf{6}$ pseudo[2]rotaxane by de-threading of one ammonium axle. Finally, ${ }^{1} \mathrm{H}$ NMR and COSY spectra of the 1:3 mixture of $\mathbf{8}^{+} \cdot \mathrm{TFPB}^{-}$and $\mathbf{6}$, once again evidenced the absence of shielded benzylic resonances in the 4-6 ppm region, and this can be considered a clear-cut proof that endo-butyl pseudo[3]rotaxane and pseudo[4]rotaxane were selectively formed (Figure 11).

\section{Conclusion}

In this study we described the synthesis of a triple-calix[6]arene host (6) in which three pentamethoxy-mono-hydroxy units are linked to a central 1,3,5-trimethylbenzene moiety. We have shown that $\mathbf{6}$ is able to give multiple-threading processes in the presence of dipentylammonium or dibenzylammonium axles. The formation of pseudo[2]rotaxanes, pseudo[3]rotaxanes, and pseudo[4]rotaxanes in $\mathrm{CDCl}_{3}$ solution was ascertained by $1 \mathrm{D}$ and 2D NMR, DOSY, and ESI-FT-ICR MS/MS experiments. In addition, in the presence of a directional butylbenzylammonium axle, the stereoselective formation of endo-alkyl pseudorotaxane stereoisomers was observed.

\section{Experimental}

HR mass spectra were acquired on a FT-ICR mass spectrometer equipped with a $7 \mathrm{~T}$ magnet. The mass spectra were calibrated externally, and a linear calibration was applied. All chemicals were reagent grade and were used without further purification. Tetrahydrofuran was dried by heating under reflux over sodium wire in the presence of benzophenone as indicator while dimethylformamide was dried by activated $3 \AA$ molecular sieves. When necessary the compounds were dried in vacuum over $\mathrm{CaCl}_{2}$. Reactions were monitored by TLC silica gel plates $(0.25 \mathrm{~mm})$ and visualized by $254 \mathrm{~nm}$ UV light, or by spraying with $\mathrm{H}_{2} \mathrm{SO}_{4}-\mathrm{Ce}\left(\mathrm{SO}_{4}\right)_{2}$. The derivative 9 has been synthesized according to literature procedures [27]. NMR spectra were recorded on a $600\left[600\left({ }^{1} \mathrm{H}\right)\right.$ and $\left.150 \mathrm{MHz}\left({ }^{13} \mathrm{C}\right)\right]$ spectrometer. Chemical shifts are reported relative to the residual solvent peak. COSY spectra were taken using a relaxation delay of $2 \mathrm{~s}$ with 30 scans and 170 increments of 2048 points each. HSQC spectra were performed with gradient selection, sensitivity enhancement, and phasesensitive mode using the Echo/AntiechoTPPI procedure.

Synthesis of derivative 6. In a dry round flask, under $\mathrm{N}_{2}$, derivative 8 (3.11 g, $2.98 \mathrm{mmol})$ was dissolved in dry THF/DMF (180 mL, 7:3 v/v). Subsequently, NaH (1.05 g, $43.86 \mathrm{mmol})$ was added at $0{ }^{\circ} \mathrm{C}$. After 15 minutes, 1,3,5-tris(bromomethyl)benzene $(0.36 \mathrm{~g}, 1.00 \mathrm{mmol})$ was added to the reaction mixture at room temperature. The reaction was stirred at reflux for $12 \mathrm{~h}$ under a nitrogen atmosphere. Afterwards the reaction was stopped by addition of $1 \mathrm{M} \mathrm{HCl}$ and the solution was extracted with chloroform. The organic phase was dried over anhydrous $\mathrm{Na}_{2} \mathrm{SO}_{4}$, filtered and evaporated of the solvent. The raw was purified through chromatography column on silica gel and using solvent mixture dichloromethane/diethyl ether 96:4 as 

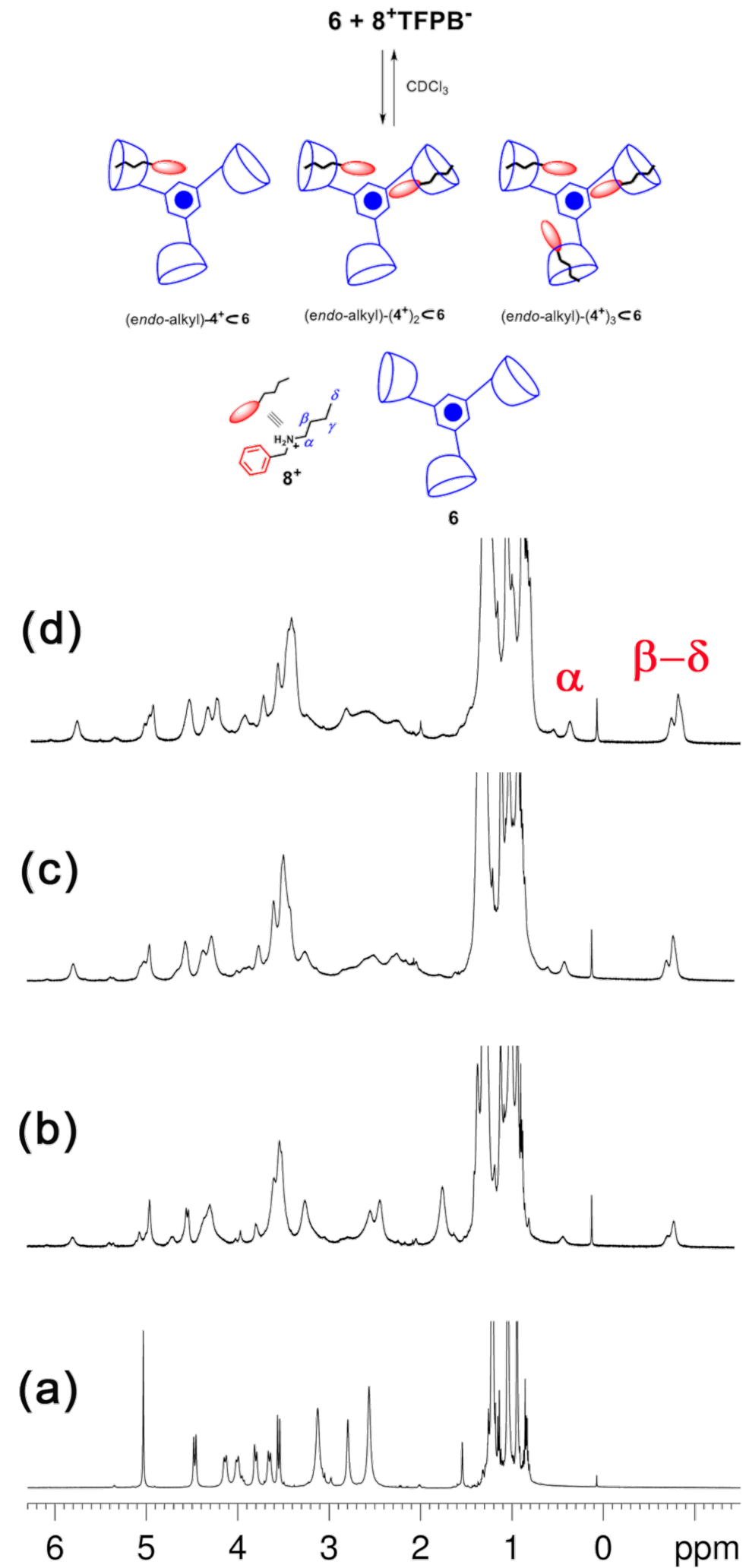

Figure 11: (a-d) ${ }^{1} \mathrm{H}$ NMR titration of 6 with $\mathbf{8}^{+} \cdot \mathrm{TFPB}^{-}\left(\mathrm{CDCl}_{3}, 298 \mathrm{~K}, 600 \mathrm{MHz}\right)$. Significant portions of the ${ }^{1} \mathrm{H}$ NMR spectra of: (a) $\mathbf{6}$; (b) 1:1, (c) $1: 2$, (d) $1: 3$, mixture of $\mathbf{6}$ and $\mathbf{8}^{+} \cdot$ TFPB $^{-}$. (Top) Formation of the $\mathbf{8}^{+} \subset \mathbf{6},\left(\mathbf{8}^{+}\right)_{2} \subset \mathbf{6},\left(\mathbf{8}^{+}\right)_{3} \subset \mathbf{6}$ pseudorotaxane architectures (sketch) by multiple-threading of $\mathbf{6}$ with $8^{+}$as $\mathrm{TFPB}^{-}$salt. 
eluents. Derivative 6 was isolated with $68 \%$ yield $(2.20 \mathrm{~g}$, $0.67 \mathrm{mmol}$ ). ${ }^{1} \mathrm{H} \mathrm{NMR}\left(600 \mathrm{MHz}, \mathrm{CDCl}_{3}, 298 \mathrm{~K}\right) \delta 7.76$ (s, $\mathrm{ArH}, 3 \mathrm{H}$ ), 7.23-7.22 (overlapped, $\mathrm{ArH} \mathrm{C}_{\text {calix }}, 6 \mathrm{H}$ ), 7.08-7.04 (overlapped, $\mathrm{Ar} H_{\text {calix }}, 12 \mathrm{H}$ ), 6.91-6.84 (overlapped, $\mathrm{Ar} H_{\text {calix }}$, $18 \mathrm{H}$ ), 5.03 (s, $\mathrm{OCH}_{2} \mathrm{Ar}, 6 \mathrm{H}$ ), 4.47 and 3.55 (AX system, $\mathrm{ArCH}_{2} \mathrm{Ar}, J=14.7 \mathrm{~Hz}, 12 \mathrm{H}$ ), 4.14 and 3.65 (AX system, ArCH${ }_{2} \mathrm{Ar}, J=14.5 \mathrm{~Hz}, 12 \mathrm{H}$ ), 4.01 and 3.80 (AX system, $\left.\mathrm{ArCH}_{2} \mathrm{Ar}, J=14.2 \mathrm{~Hz}, 12 \mathrm{H}\right), 3.12\left(\mathrm{~s}, \mathrm{OCH}_{3}, 18 \mathrm{H}\right), 2.80$ (s, $\left.\mathrm{OCH}_{3}, 9 \mathrm{H}\right), 2.56\left(\mathrm{~s}, \mathrm{OCH}_{3}, 18 \mathrm{H}\right), 1.22-1.21$ (overlapped, $\left.\mathrm{C}\left(\mathrm{CH}_{3}\right)_{3}, 81 \mathrm{H}\right), 1.05\left(\mathrm{~s}, \mathrm{C}\left(\mathrm{CH}_{3}\right)_{3}, 54 \mathrm{H}\right), 0.95\left(\mathrm{~s}, \mathrm{C}\left(\mathrm{CH}_{3}\right)_{3}\right.$, $27 \mathrm{H}) ;{ }^{13} \mathrm{C} \mathrm{NMR}\left(75 \mathrm{MHz}, \mathrm{CDCl}_{3}, 298 \mathrm{~K}\right) \delta 154.5,154.4$, 153.9, 152.4, 145.9, 145.7, 138.7, 134.1, 133.8, 133.7, 133.6, 133.4, 127.5, 126.7, 125.8, 125.5, 125.2, 124.6, 74.7, 60.1, 60.0, $34.3,34.2,31.7,31.6,31.5,31.4,30.8,30.5,29.0,19.6$; HRMS $(\mathrm{m} / \mathrm{z})$ : calcd for $\mathrm{C}_{222} \mathrm{H}_{288} \mathrm{KO}_{18}{ }^{+}$, 3283.1319; found, 3283.1748 .

Preparation of pseudo $[n]$ rotaxane. Derivative $6(5.00 \mathrm{mg}$, $\left.1.5 \times 10^{-3} \mathrm{mmol}\right)$ and dialkylammonium axle $4^{+}, 7^{+}$or $\mathbf{8}^{+}$ $\left[n \times\left(1.5 \times 10^{-3} \mathrm{mmol}\right), n=1-6\right]$ were dissolved in $0.5 \mathrm{~mL}$ of $\mathrm{CDCl}_{3}$. Then, the solution was sonicated for $5 \mathrm{~min}$ and transferred in a NMR tube for 1D and 2D NMR spectra acquisition.

Determination of $\boldsymbol{K}_{\text {app }}$ values by quantitative ${ }^{\mathbf{1}} \mathrm{H}$ NMR analysis. The samples were prepared by dissolving 6 $\left(1.5 \times 10^{-3} \mathrm{mmol}\right)$ and the appropriate alkylammonium guest $4^{+}, 7^{+}$or $8^{+}$as $\mathrm{TFPB}^{-}$salt $\left(1.5 \times 10^{-3} \mathrm{mmol}\right)$ in $\mathrm{CDCl}_{3}$ $(0.5 \mathrm{~mL})$ containing $1 \mu \mathrm{L}$ of $1,1,2,2$-tetrachloroethane $(d=1.586 \mathrm{~g} / \mathrm{mL}, 0.019 \mathrm{M})$ as internal standard (IS). The complex concentration [complex] was evaluated by integration of the ${ }^{1} \mathrm{H}$ NMR signals of 1,1,2,2-tetrachloroethane vs the shielded signals of the guest molecules. The following equation was used to obtain the moles of the complex:

$$
\frac{G a}{G b}=\frac{F a}{F b} \times \frac{N b}{N a} \times \frac{M a}{M b}
$$

Where: $G a=$ grams of IS; $G b=$ grams of complex, $F a$ and $F b=$ areas of the signals of 1,1,2,2-tetrachloroethane and signal of the guest, $N a$ and $N b=$ numbers of nuclei which cause the signals ( $\mathrm{Na}$ for IS $=2$; $\mathrm{Nb}$ for guest) and $M a$ and $M b=$ molecular masses of IS (a) and complex (b)

\section{Supporting Information}

\section{Supporting Information File 1}

${ }^{1} \mathrm{H}$ and ${ }^{13} \mathrm{C}$ NMR spectra, ${ }^{1} \mathrm{H}$ qNMR spectra, 2D COSY

and HSQC spectra of pseudorotaxanes.

[https://www.beilstein-journals.org/bjoc/content/

supplementary/1860-5397-15-207-S1.pdf]

\section{Acknowledgements}

The authors acknowledge the Regione Campania (POR CAMPANIA FESR 2007/2013 O.O.2.1, CUP B46D14002660009) for the FT-ICR mass spectrometer facilities, Farma-BioNet (CUP B25C13000230007), the Centro di Tecnologie Integrate per la Salute" (CITIS) (project PONa3_00138) for the 600 MHz NMR facilities and Università di Salerno for financial support. Financial support is acknowledged from the Università di Salerno (FARB 2017 "SINTESI E STUDIO DELLE PROPRIETÀ DI NUOVI DERIVATI

\section{CICLOPARAFENILENICI")}

\section{ORCID ${ }^{\circledR}$ iDs}

Carmen Talotta - https://orcid.org/0000-0002-2142-6305 Margherita De Rosa - https://orcid.org/0000-0001-7451-5523 Placido Neri - https://orcid.org/0000-0003-4319-1727

\section{References}

1. Swiegers, G. F. Self-Assembly: Terminology. In Encylopedia of Supramolecular Chemistry; Steed, J. W.; Atwood, J. L., Eds.; Marcel Dekker: New York, NY, USA, 2004; pp 1263-1269. doi:10.1081/e-esmc-120012878

2. Yao, X.; Wang, X.; Jiang, T.; Ma, X.; Tian, H. Langmuir 2015, 31, 13647-13654. doi:10.1021/acs.langmuir.5b04083

3. Yao, X.; Li, T.; Wang, S.; Ma, X.; Tian, H. Chem. Commun. 2014, 50, 7166-7168. doi:10.1039/c4cc02672a

4. Yao, X.; Ma, X.; Tian, H. J. Mater. Chem. C 2019. doi:10.1039/c9tc03257f

5. Bruns, C. J.; Stoddart, J. F. The Nature of the Mechanical Bond: From Molecules to Machines, 1st ed.; John Wiley \& Sons: Hoboken, New Jersey, 2017. doi:10.1002/9781119044123

6. Feringa, B. L. Angew. Chem., Int. Ed. 2017, 56, 11060-11078. doi:10.1002/anie.201702979

7. Sauvage, J.-P. Angew. Chem., Int. Ed. 2017, 56, 11080-11093. doi:10.1002/anie.201702992

8. Stoddart, J. F. Angew. Chem., Int. Ed. 2017, 56, 11094-11125. doi:10.1002/anie.201703216

9. Sauvage, J.-P.; Dietrich-Buchecker, C., Eds. Molecular Catenanes, Rotaxanes and Knots: A Journey Through the World of Molecular Topology; Wiley-VCH: Weinheim, Germany, 1999. doi:10.1002/9783527613724

10. Ashton, P. R.; Reder, A. S.; Spencer, N.; Stoddart, J. F. J. Am. Chem. Soc. 1993, 115, 5286-5287. doi:10.1021/ja00065a046

11. Weidmann, J.-L.; Kern, J.-M.; Sauvage, J.-P.; Muscat, D.; Mullins, S.; Köhler, W.; Rosenauer, C.; Räder, H. J.; Martin, K.; Geerts, Y. Chem. - Eur. J. 1999, 5, 1841-1851.

doi:10.1002/(sici)1521-3765(19990604)5:6<1841::aid-chem1841>3.0.c $0 ; 2-q$

12. Li, Z.-T.; Becher, J. Chem. Commun. 1996, 639-640. doi:10.1039/cc9960000639

13. Frey, J.; Kraus, T.; Heitz, V.; Sauvage, J.-P. Chem. Commun. 2005, 5310-5312. doi:10.1039/b509745b

14. Frey, J.; Kraus, T.; Heitz, V.; Sauvage, J.-P. Chem. - Eur. J. 2007, 13, 7584-7594. doi:10.1002/chem.200700671

15. Evans, N. H.; Serpell, C. J.; Beer, P. D. Angew. Chem., Int. Ed. 2011, 50, 2507-2510. doi:10.1002/anie.201007741 
16. Yang, L.; Langer, P.; Davies, E. S.; Baldoni, M.; Wickham, K.; Besley, N. A.; Besley, E.; Champness, N. R. Chem. Sci. 2019, 10, 3723-3732. doi:10.1039/c9sc00167k

17. Gaeta, C.; Troisi, F.; Neri, P. Org. Lett. 2010, 12, 2092-2095. doi:10.1021/ol100578z

18. Gaeta, C.; Talotta, C.; Margarucci, L.; Casapullo, A.; Neri, P. J. Org. Chem. 2013, 78, 7627-7638. doi:10.1021/jo401206j

19. Talotta, C.; De Simone, N. A.; Gaeta, C.; Neri, P. Org. Lett. 2015, 17, 1006-1009. doi:10.1021/acs.orglett.5b00115

20. Gaeta, C.; Talotta, C.; Farina, F.; Campi, G.; Camalli, M.; Neri, P. Chem. - Eur. J. 2012, 18, 1219-1230. doi:10.1002/chem.201102179

21. Gaeta, C.; Talotta, C.; Farina, F.; Teixeira, F. A.; Marcos, P. M.; Ascenso, J. R.; Neri, P. J. Org. Chem. 2012, 77, 10285-10293. doi:10.1021/j03019945

22. Talotta, C.; Gaeta, C.; De Rosa, M.; Ascenso, J. R.; Marcos, P. M.; Neri, P. Eur. J. Org. Chem. 2016, 158-167. doi:10.1002/ejoc.201501319

23. Pierro, T.; Gaeta, C.; Talotta, C.; Casapullo, A.; Neri, P. Org. Lett. 2011, 13, 2650-2653. doi:10.1021/ol200753c

24. Talotta, C.; Gaeta, C.; Neri, P. Org. Lett. 2012, 14, 3104-3107. doi:10.1021/ol3011997

25. Gaeta, C.; Talotta, C.; Mirra, S.; Margarucci, L.; Casapullo, A.; Neri, P. Org. Lett. 2013, 15, 116-119. doi:10.1021/ol303142c

26. Gaeta, C.; Talotta, C.; De Rosa, M.; Soriente, A.; Neri, P. In Calixarenes and Beyond; Neri, P.; Sessler, J. L.; Wang, M.-X., Eds.; Springer: Dordrecht, Netherlands, 2016; pp 783-809. doi:10.1007/978-3-319-31867-7_30

27. Ciao, R.; Talotta, C.; Gaeta, C.; Margarucci, L.; Casapullo, A.; Neri, P. Org. Lett. 2013, 15, 5694-5697. doi:10.1021/ol4026974

28. Ciao, R.; Talotta, C.; Gaeta, C.; Neri, P. Supramol. Chem. 2014, 26 , 569-578. doi:10.1080/10610278.2013.872248

29. de Mendoza, J.; Carramolino, M.; Cuevas, F.; Nieto, P. M.; Prados, P.; Reinhoudt, D. N.; Verboom, W.; Ungaro, R.; Casnati, A. Synthesis 1994, 47-50. doi:10.1055/s-1994-25403

30. De Rosa, M.; Soriente, A.; Concilio, G.; Talotta, C.; Gaeta, C.; Neri, P. J. Org. Chem. 2015, 80, 7295-7300. doi:10.1021/acs.joc.5b00978

31. Arduini, A.; Orlandini, G.; Secchi, A.; Credi, A.; Silvi, S.; Venturi, M. In Calixarenes and Beyond; Neri, P.; Sessler, J. L.; Wang, M.-X., Eds.; Springer: Dordrecht, Netherlands, 2016; pp 761-781. doi:10.1007/978-3-319-31867-7_29

32. Arduini, A.; Bussolati, R.; Credi, A.; Secchi, A.; Silvi, S.; Semeraro, M.; Venturi, M. J. Am. Chem. Soc. 2013, 135, 9924-9930. doi:10.1021/ja404270c

33. Arduini, A.; Calzavacca, F.; Pochini, A.; Secchi, A. Chem. - Eur. J. 2003, 9, 793-799. doi:10.1002/chem.200390089

34. Arduini, A.; Ciesa, F.; Fragassi, M.; Pochini, A.; Secchi, A. Angew. Chem., Int. Ed. 2005, 44, 278-281. doi:10.1002/anie.200461336

35. Arduini, A.; Credi, A.; Faimani, G.; Massera, C.; Pochini, A.; Secchi, A.; Semeraro, M.; Silvi, S.; Ugozzoli, F. Chem. - Eur. J. 2008, 14, 98-106. doi:10.1002/chem.200700748

36. Arduini, A.; Bussolati, R.; Credi, A.; Monaco, S.; Secchi, A.; Silvi, S.; Venturi, M. Chem. - Eur. J. 2012, 18, 16203-16213. doi:10.1002/chem.201201625

37. Zanichelli, V.; Ragazzon, G.; Arduini, A.; Credi, A.; Franchi, P.; Orlandini, G.; Venturi, M.; Lucarini, M.; Secchi, A.; Silvi, S. Eur. J. Org. Chem. 2016, 1033-1042. doi:10.1002/ejoc.201501522

38. La Manna, P.; Talotta, C.; Gaeta, C.; Soriente, A.; De Rosa, M.; Neri, P. J. Org. Chem. 2017, 82, 8973-8983.

doi:10.1021/acs.joc.7b01388
39. Talotta, C.; Gaeta, C.; Qi, Z.; Schalley, C. A.; Neri, P. Angew. Chem., Int. Ed. 2013, 52, 7437-7441. doi:10.1002/anie.201301570

\section{License and Terms}

This is an Open Access article under the terms of the Creative Commons Attribution License (http://creativecommons.org/licenses/by/4.0). Please note that the reuse, redistribution and reproduction in particular requires that the authors and source are credited.

The license is subject to the Beilstein Journal of Organic Chemistry terms and conditions:

(https://www.beilstein-journals.org/bjoc)

The definitive version of this article is the electronic one which can be found at: doi:10.3762/bjoc. 15.207 